\title{
Sistem Pendukung Keputusan Penerimaan Beasiswa Bidik Misi di POLIBAN Dengan Metode SA W Berbasis Web
}

\author{
Reza Fauzan ${ }^{1}$, Yoenie Indrasary ${ }^{2}$, Nonik Muthia ${ }^{3}$ \\ ${ }^{1,2,3}$ Politeknik Negeri Banjarmasin \\ ${ }^{1}$ reza.fauzan@poliban.ac.id, ${ }^{2}$ indrasay@gmail.com, ${ }^{3}$ snonikmuthia19@gmail.com
}

\begin{abstract}
The scholarship program is an educational tuition program for prospective students who are economically disadvantaged and have good academic potential to study at universities. Scholarship recipients are determined based on certain criteria. Decision support system is a system used to determine the alternative of Scholarship recipients in the State Polytechnic of Banjarmasin which is closest to the criteria that have been determined by using Simple Additive Weighting (SAW) method. The basic concept of the Simple Additive Weighting method is to find the sum of the weighted from performance ratings on each alternative on all criteria. The test is done with new data (test data) from the alternative of Scholarship Audience. The test data is normalized according to the type of attribute criteria (benefit or cost). The final result is obtained from the calculation process, which is the sum of the normalized matrix with the weight per criterion showing the alternative rank of the scholarship recipient from the closest to the criteria to the farthest from the criterion. From there was obtained an alternative which then get Scholarship.
\end{abstract}

Keywords- Alternative of Scholarship recipients, Simple Additive Weighting (SAW), Decision support system

Abstrak- Program beasiswa Bidik Misi adalah program bantuan biaya pendidikan bagi calon mahasiswa tidak mampu secara ekonomi dan memiliki potensi akademik baik untuk menempuh pendidikan di perguruan tinggi. Penerima Beasiswa Bidik Misi ditentukan berdasarkan kriteria tertentu. Sistem pendukung keputusan merupakan sebuah sistem yang digunakan untuk menentukan alternatif penerima Beasiswa Bidik Misi di Politeknik Negeri Banjarmasin yang paling mendekati kriteria yang telah ditentukan dengan menggunakan metode Simple Additive Weighting (SAW). Konsep dasar dari metode Simple Additive Weighting ini adalah mencari penjumlahan terbobot dari rating kinerja pada setiap alternatif pada semua kriteria. Pengujian dilakukan dengan data baru (data uji) dari alternatif penerima Beasiswa Bidik Misi data uji tersebut dinormalisasi sesuai dengan jenis atribut kriteria (benefit atau cost). Hasil akhir diperoleh dari proses perhitungan, yaitu penjumlahan dari matriks ternormalisasi dengan bobot per kriteria yang menunjukkan rangking alternatif penerima beasiswa dari yang paling mendekati kriteria hingga yang paling jauh dari kriteria. Dari sana lah didapat alternatif yang kemudian mendapat Beasiswa Bidik Misi.

Kata kunci- Alternatif penerima beasiswa, Simple Additive Weighting (SAW), Sistem Pendukung Keputusan

\section{PENDAHULUAN}

Program beasiswa Bidik Misi adalah program bantuan biaya pendidikan bagi calon mahasiswa tidak mampu secara ekonomi dan memiliki potensi akademik baik untuk menempuh pendidikan di perguruan tinggi. Penerima Beasiswa Bidik Misi ditentukan berdasarkan kriteria tertentu yang telah ditetapkan oleh Kementerian Riset Teknologi dan Pendidikan Tinggi [10].

Sistem pendukung keputusan (SPK) adalah bagian dari sistem informasi berbasis komputer termasuk sistem berbasis pengetahuan atau menajemen pengetahuan yang dipakai untuk mendukung pengambilan keputusan dalam suatu organisasi atau perusahaan. Dapat juga dikatakan sebagai sistem komputer yang mengolah data menjadi informasi untuk mengambil keputusan dari masalah semi terstruktur yang spesifik [11].

Metode Simple Additive Weighting (SAW) merupakan metode penjumlahan terbobot. Konsep dasar metode Simple Additive Weighting (SAW) adalah mencari penjumlahan terbobot dari rating kinerja pada setiap alternatif pada semua kriteria. Metode Simple Additive Weighting (SAW) membutuhkan proses normalisasi matrik keputusan (X) ke suatu skala yang dapat diperbandingkan dengan semua rating alternatif yang ada [12].

\section{METODE PENELITIAN}

A. Alur Sistem

Alur sistem yang dibangun dapat dilihat pada gambar berikut : 


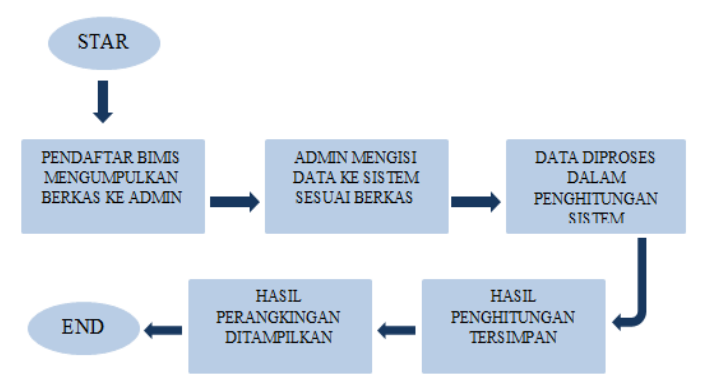

Gambar 1. Alur Sistem

Pertama mahasiswa pendaftar Beasiswa Bidik Misi mengumpulkan berkas ke bagian akademik Politeknik Negeri Banjarmasin dan telah mendaftarkan diri pada situs resmi Ristekdikti untuk melakukan pendaftaran online.

Setelah berkas masuk ke bagian akademik Politeknik Negeri Banjarmasin, admin memasukkan data mahasiswa ke dalam database sistem hingga data pendaftar terakhir.

Admin memproses data tersebut hingga ke perhitungan Simple Additive Weighting, dan hasil perhitungan dapat ditampilkan dan disimpan ke database sistem.

Admin dapat menampilkan hasil perangkingan dari perhitungan sebagai laporan. Dan didapatkan hasil mahasiswa yang diajukan sebagai penerima Beasiswa Bidik Misi sesuai dengan kuota yang ditentukan.

\section{B. Perhitungan Dengan Simple Additive Weighting (SAW)}

Berikut adalah langkah-langkah penghitungan dengan metode Simple Additive Weighting (SAW) :

1. Menentukan Alternatif (Ai)

2. Menentukan kriteria yang akan dijadikan acuan dalam pengambilan keputusan $(\mathrm{Cj})$

3. Menentukan bobot preferensi atau tingkat kepentingan (W) setiap kriteria

4. Menentukan Nilai Kecocokan setiap kriteria

5. Membuat matrik keputusan (X) yang didapat dari rating kecocokan pada setiap alternatif (Ai) dengan setiap kriteria $(\mathrm{Cj})$.

6. Melakukan langkah normalisasi matriks keputusan (X) dengan cara menghitung nilai rating kinerja ternormalisasi (rij) dari alternatif (Ai) pada kriteria (Cj) dengan rumus :

$r_{i j}=\left\{\frac{x_{i j}}{\operatorname{Max}_{i} x_{i j}}\right\}$

Jika $\mathrm{j}$ adalah atribut keuntungan (benefit)

$r_{i j}=\left\{\frac{\operatorname{Min}_{i} x_{i j}}{x_{i j}}\right\}$

Jika $\mathrm{j}$ adalah atribut biaya (cost)

7. Hasil dari normalisasi (rij) membentuk matrik ternormalisasi $(\mathrm{R})$.

$$
R=\left[\begin{array}{cccc}
r_{11} & r_{12} & \ldots & r_{1 j} \\
\vdots & & & \vdots \\
r_{i 1} & r_{i 2} & \ldots & r_{i j}
\end{array}\right]
$$

8. Hasil akhir nilai preferensi (Vi) diperoleh dari penjumlahan dari perkalian elemen baris matrik ternormalisasi (R) dengan bobot preferensi (W) yang bersesuaian elemen kolom matrik (W).

$$
V_{I}=\sum_{j=1}^{n} w_{j} r_{i j}
$$

Dengan :

$V_{I}=$ rangking untuk setiap alternatif

$w_{j}=$ nilai bobot dari setiap kriteria

$r_{i j}=$ nilai rating kinerja ternormalisasi.

C. Rancangan Data Flow Diagram (DFD)

Rancangan sistem berupa Data Flow Diagram (DFD) level 0 digambarkan seperti berikut :

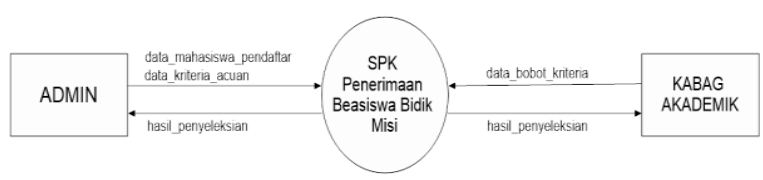

Gambar 2. Data Flow Diagram (DFD) Level 0

Pada gambar Data Flow Diagram level 0 diatas, terdapat dua entitas yang berhubungan langsung dengan Sistem Pendukung Keputusan Penerimaan Beasiswa Bidik Misi. Yaitu entitas admin dan kabag akademik. Admin dapat mengelola data mahasiswa pendaftar Bidik Misi dan data kriteria acuan, dan melihat hasil penyeleksian. Sedangkan kabag akademik dapat mengelola data bobot kriteria pada sistem dan melihat hasil penyeleksian.

Rancangan sistem berupa Data Flow Diagram (DFD) level 1 digambarkan seperti berikut :

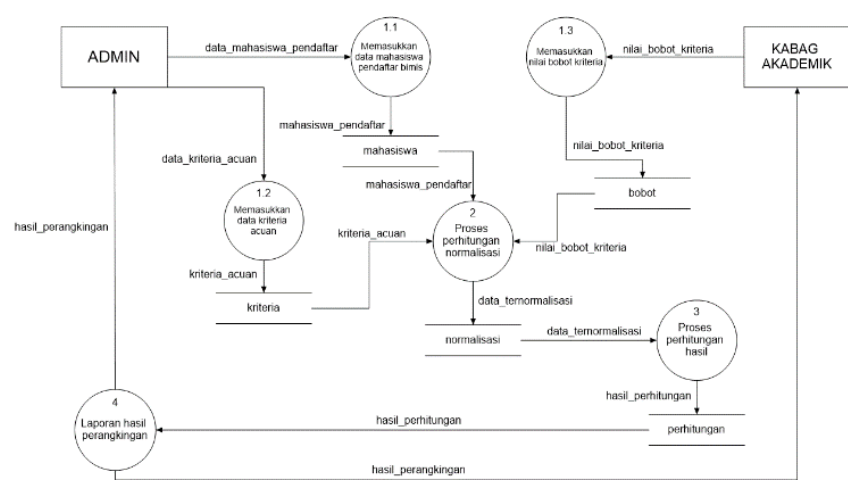

Gambar 3. Data Flow Diagram (DFD) level 1

Pada Data Flow Diagram level 1 diatas, terdapat 4 proses yaitu :

1. Proses pertama adalah proses pendataan atau memasukkan data ke dalam tabel-tabel.

- Admin memasukkan Data mahasiswa pendaftar dan masuk ke dalam tabel mahasiswa. 
- Admin memasukkan data kriteria acuan, dan masuk ke dalam tabel kriteria.

- Kabag Akademik memasukkan nilai bobot kriteria, dan masuk ke dalam tabel bobot.

2. Proses kedua adalah proses perhitungan normalisasi, yang datanya didapat dari tabel mahasiswa, tabel kriteria, dan tabel bobot. Dan hasil dari proses ini masuk ke dalam tabel normalisasi.

3. Proses ketiga adalah proses perhitungan hasil, data didapat dari tabel normalisasi dan hasil perhitungan masuk ke dalam tabel perhitungan.

4. Proses keempat adalah perangkingan, data didapat dari tabel perhitungan dan selanjutnya dirangkingkan untuk dilanjutkan kepada admin dan kabag akademik.

\section{Rancangan Entity Relationship Diagram (ERD)}

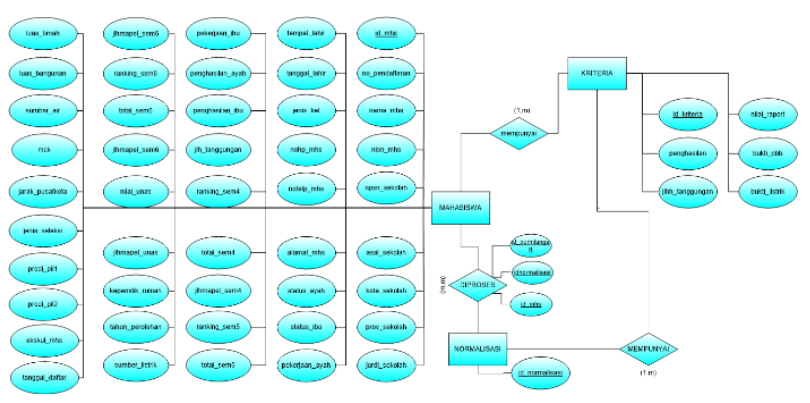

Gambar 4. Entity Relationship Diagram (ERD)

Gambar diatas adalah perancangan Entity Relationship Diagram yang merupakan rancangan database dari Sistem Pendukung Keputusan Penerimaan Beasiswa Bidik Misi. Database terdiri dari lima entitas yaitu mahasiswa, user, bobot, kriteria dan normalisasi. Entititas tersebut masing-masing memiliki atribut yang merupakan field dari tabel entitas tersebut. Entitas tersebut saling berelasi dan memiliki derajat kardinalitas. Berikut adalah relasi dan derajat kardinalitas entitas :

- Relasi antara entitas mahasiswa dan entitas kriteria memiliki derajar kardinalitas one to many.

- Relasi antara entitas kriteria dan entitas normalisasi memiliki derajar kardinalitas many to one.

- Relasi antara entitas normalisasi dan entitas mahasiswa memiliki derajat kardinalitas many to many, sehingga menghasilkan tabel baru yaitu tabel perhitungan.

\section{E. Rancangan Flowchart Sistem}

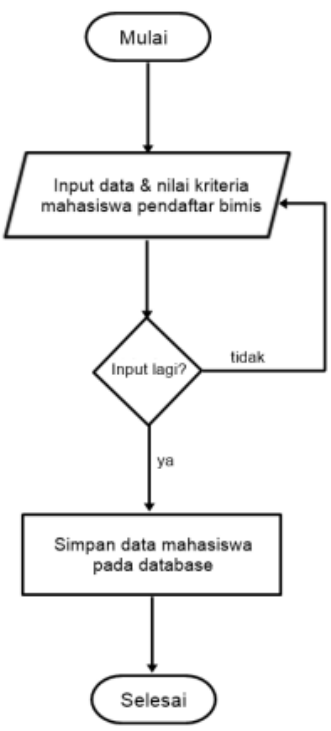

Gambar 5. Flowchart Data Mahasiswa

Gambar diatas adalah flowchart data mahasiswa. Yaitu dengan memasukkan data mahasiswa pendaftar beserta kriterianya hingga mahasiswa terakhir. Jika sudah sampai mahasiswa terakhir maka data akan disimpan pada database.

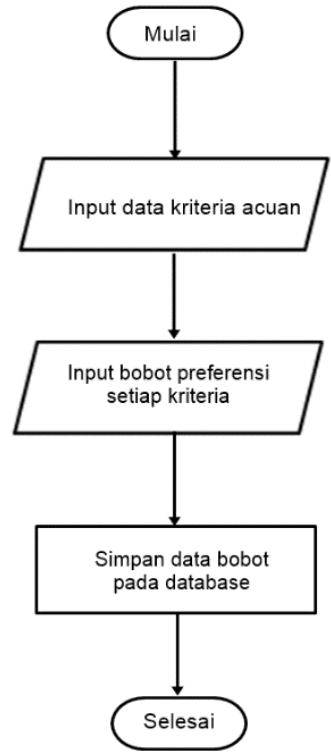

Gambar 6. Flowchart Kriteria Acuan dan Bobot

Pada flowchart kriteria acuan dan bobot, penambahan bobot sesuai dengan kriteria. Yaitu dengan memasukkan data kriteria acuan terlebih dahulu, dan selanjutnya dimasukkan bobot preferensi dari setiap kriteria acuan tersebut. Selanjutnya simpan data bobot pada database. 


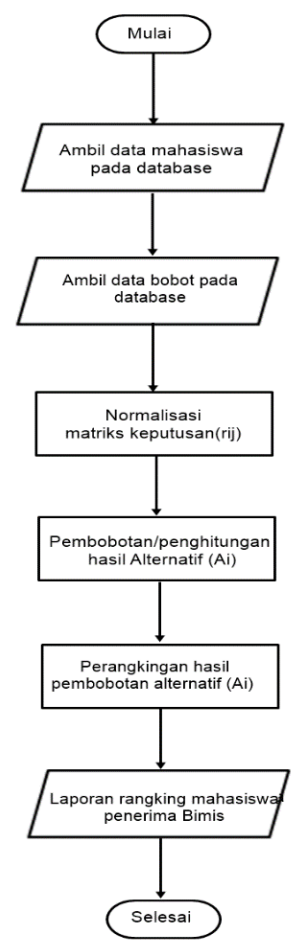

Gambar 7. Flowchart Penghitungan SAW

Pada flowchart penghitugan SAW, proses pertama adalah mengambil data mahasiswa pada database. Data mahasiswa tersebut adalah data yang diperlukan saja sesuai dengan kriteria acuan. Selanjutnya adalah mengambil data bobot masing-masing kriteria acuan dari database. Untuk selanjutnya dilakukan normalisasi data sesuai dengan kriteria acuan (benefit atau cost). Setelah data yang telah dinormalisasi didapatkan, maka dilakukan penghitungan dan didapatkan hasil akhir dari masingmasing alternatif. Selanjutnya hasil tersebut dirangkingkan dari yang terbesar hingga terkecil, agar diketahui mahasiswa yang mendapat Beasiswa Bidik Misi menyesuaikan dengan kuota yang tersedia.

\section{HASIL DAN PEMBAHASAN}

\section{A. Hasil Perhitungan Dengan Data Uji}

Tabel 1.Alternatif Penerima Beasiswa

\begin{tabular}{|c|c|c|c|c|c|}
\hline Alternatif & $\begin{array}{c}\text { Penghasilan } \\
\text { orang tua }\end{array}$ & $\begin{array}{c}\text { Jumlah } \\
\text { Tanggungan }\end{array}$ & $\begin{array}{c}\text { Rata-rata nilai raport } \\
\text { semester 4-5 }\end{array}$ & $\begin{array}{c}\text { Bukti } \\
\text { Rekening } \\
\text { Listrik }\end{array}$ & $\begin{array}{c}\text { Bukti } \\
\text { Pembayaran } \\
\text { PBB }\end{array}$ \\
\hline ke 1 & 1500000 & 4 & 83,5416666666667 & 140000 & 18000 \\
\hline ke 2 & 1250000 & 4 & 87,821969696970 & 150000 & 20000 \\
\hline ke 3 & 1250000 & 4 & 92,2916666666667 & 140000 & 18000 \\
\hline ke 4 & 750000 & 3 & 89,858333333333 & 150000 & 20000 \\
\hline ke 5 & 1250000 & 3 & 88,0583000000000 & 140000 & 18000 \\
\hline ke 6 & 1500000 & 2 & 85,954700000000 & 150000 & 20000 \\
\hline ke 7 & 2500000 & 2 & 84,3452000000000 & 140000 & 18000 \\
\hline ke 8 & 1750000 & 3 & 85,117600000000 & 150000 & 20000 \\
\hline ke 9 & 1000000 & 6 & 83,7352000000000 & 140000 & 18000 \\
\hline ke 2154 & 1250000 & 3 & 92,291666666667 & 140000 & 18000 \\
\hline
\end{tabular}

Langkah kedua adalah menentukan kriteria yang akan dijadikan acuan dalam pengambilan keputusan (Cj). Berikut adalah kriteria acuan dalam penerimaan beasiswa Bidik Misi :

\begin{tabular}{ll}
\multicolumn{2}{c}{ Tabel 2.Kriteria Acuan } \\
\hline Keterangan & Kriteria Cj) \\
\hline Penghasilan orang tua & $\mathrm{C} 1$ \\
Jumlah tanggungan & $\mathrm{C} 2$ \\
Rata-rata nilai raport semester 4-5 & $\mathrm{C} 3$ \\
Bukti rekening listrik & $\mathrm{C} 4$ \\
Bukti pembayaran PBB & $\mathrm{C} 5$ \\
\hline
\end{tabular}

Selanjutnya adalah menentukan bobot preferensi atau tingkat kepentingan (W) setiap kriteria. Bobot preferensi kriteria yang telah ditentukan adalah $\mathrm{W}=[5,4,4,3,2]$. Setelah bobot setiap kriteria ditetapkan, maka selanjutnya adalah menentukan nilai kecocokan dari setiap kriteria. Berdasarkan kriteria acuan, ditetapkan nilai kecocokannya adalah sebagai berikut :

\begin{tabular}{ll}
\multicolumn{2}{l}{ Tabel } \\
\hline Kriteria $(\mathbf{C j})$ & Kecocokan \\
\hline $\mathrm{C} 1$ & Cost \\
$\mathrm{C} 2$ & Benefit \\
$\mathrm{C} 3$ & Benefit \\
$\mathrm{C} 4$ & Cost \\
$\mathrm{C} 5$ & Cost \\
\hline
\end{tabular}

Langkah selanjutnya adalah melakukan normalisasi matriks keputusan $(\mathrm{X})$ dengan cara menghitung nilai rating kinerja ternormalisasi (rij) dari alternatif (Ai) pada kriteria $(\mathrm{Cj})$ sesuai dengan nilai kecocokannya.

Matriks keputusan (W) didapat dari data alternatif penerima bidik misi, yaitu sebagai berikut :

$\begin{array}{lllll}750000 & 3 & 89,858333333333 & 150000 & 20000 \\ 1250000 & 3 & 88,058300000000 & 140000 & 18000 \\ 1500000 & 2 & 85,954700000000 & 150000 & 20000 \\ 2500000 & 2 & 84,345200000000 & 140000 & 18000 \\ 1750000 & 3 & 85,117600000000 & 150000 & 20000 \\ 1000000 & 6 & 83,735200000000 & 140000 & 18000 \\ 1250000 & 3 & 92,291666666667 & 140000 & 18000\end{array}$

Kemudian matriks diatas dinormalisasi dengan penghitungan sesuai dengan kecocokan kriteria masingmasing data (benefit/cost). Sehingga terbentuk matrik ternormalisasi (R) 


$\begin{array}{ccccc}0,5 & 0,666666667 & 0,905191874 & 1 & 1 \\ 0,6 & 0,666666667 & 0,951569875 & 0,933333333 & 0,9 \\ 0,6 & 0,666666667 & 1 & 1 & 1 \\ 1 & 0,5 & 0,973634312 & 0,933333333 & 0,9 \\ 0,6 & 0,5 & 0,954130564 & 1 & 1 \\ 0,5 & 0,333333333 & 0,931337607 & 0,933333333 & 0,9 \\ 0,3 & 0,333333333 & 0,91389833 & 1 & 1 \\ 0,428571429 & 0,5 & 0,922267449 & 0,933333333 & 0,9 \\ 0,75 & 1 & 0,907288849 & 1 & 1 \\ 0,6 & 0,5 & 0,595936795 & 1 & 1\end{array}$

Langkah selanjutnya adalah penghitungan hasil akhir nilai preferensi (Vi) yang diperoleh dari penjumlahan dari perkalian elemen baris matrik ternormalisasi (R) dengan bobot preferensi (W) yang bersesuaian elemen kolom matrik (W). Dengan perhitungan sebagai berikut :

$$
\begin{aligned}
& \mathrm{V} 1=(5)(0,5)+(4)(0,666666667)+(4)(0,905191874)+ \\
& (3)(1)+(2)(1)=13,7874
\end{aligned}
$$$$
\mathrm{V} 2=(5)(0,6)+(4)(0,666666667)+(4)(0,951569875)+
$$$$
(3)(0,933333333)+(2)(0,9)=14,0729
$$$$
\mathrm{V} 3=(5)(0,6)+(4)(0,666666667)+(4)(1)+(3)(1)+
$$$$
(2)(1)=14,6667
$$$$
\mathrm{V} 4=(5)(1)+(4)(0,5)+(4)(0,973634312)+(3)(
$$$$
0,933333333)+(2)(0,9)=15,4945
$$$$
\mathrm{V} 5=(5)(0,6)+(4)(0,5)+(4)(0,954130564)+(3)(1)+
$$$$
\text { (2) }(1)=12,1587
$$$$
\mathrm{V} 6=(5)(0,5)+(4)(0,333333333)+(4)(0,931337607)+
$$$$
(3)(0,933333333)+(2)(0,9)=13,8165
$$$$
\mathrm{V} 7=(5)(0,3)+(4)(0,333333333)+(4)(0,91389833)+
$$$$
(3)(1)+(2)(1)=11,4889
$$

$\mathrm{V} 8=(5)(0,428571429)+(4)(0,5)+(4)(0,922267449)+$ (3) $(0,933333333)+(2)(0,9)=12,4319$

$\mathrm{V} 9=(5)(0,75)+(4)(1)+(4)(0,907288849)+(3)(1)+$ $(2)(1)=16,3792$

$\mathrm{V} 10=(5)(0,6)+(4)(0,5)+(4)(0,595936795)+(3)(1)+$ $(2)(1)=12,3837$

B. Hasil Uji Coba

Hasil dari uji coba yang telah dilakukan dapat dilihat dengan tabel berikut :

Tabel 4. Uji Coba Sistem

\begin{tabular}{rlrc}
\hline No & Fungsi & & Keberhasilan \\
\hline $\mathbf{1}$ & $\begin{array}{l}\text { Tambah, edit, hapus } \\
\text { data pendaftar }\end{array}$ & Berhasil \\
& $\begin{array}{l}\text { Ambil data } \\
\text { pendaftar dari } \\
\text { dijadikan kriteria }\end{array}$ & yang & Berhasil \\
& &
\end{tabular}

Sistem Pendukung Keputusan Penerimaan Beasiswa Bidik Misi di POLIBAN Dengan Metode SAW Berbasis Web

$\begin{array}{clr}3 & \begin{array}{l}\text { Fungsi } \\ \text { normalisasi }\end{array} & \text { Berhasil } \\ 4 & \begin{array}{l}\text { Fungsi perhitungan } \\ \text { SAW }\end{array} & \text { Berhasil } \\ \mathbf{5} & \begin{array}{l}\text { Tampilkan } \\ \text { perangkingan } \\ \text { Tambah, edit, hapus } \\ \text { data bobot }\end{array} & \text { Berhasil } \\ & \text { Berhasil }\end{array}$

Kesimpulan yang dapat diambil setelah pembuatan sistem pendukung keputusan ini adalah berdasarkan hasil pengujian dengan beberapa alternatif diperoleh kesimpulan bahwa Sistem Pendukung Keputusan Penerimaan Beasiswa Bidik Misi ini dapat dengan baik melakukan perangkingan.

Saran-saran untuk pengembangan program ini adalah perlu adanya sosialisasi ke bagian pengelola beasiswa Bidik Misi di Politeknik Negeri Banjarmasin, agar sistem ini dapat dipergunakan untuk mempermudah penyeleksian beasiswa Bidik Misi. Selain itu, perbaikan dan pengembangan harus terus dilakukan untuk menyempurnakan sistem agar benar-benar sesuai dengan harapan semua pihak.

\section{REFERENSI}

[1] Basuki, Awan. 2010. Membangun Web Berbasis PHP dengan Framework Codeigniter.Lokommedia: Yogyakarta.

[2] Basyaib, F. (2009). Teori Pembuatan Keputusan. Jakarta: PT Grasindo.

[3] Binarso, F.A.H, 2016 Sistem Pendukung Keputusan Pemilihan Gadget Smartphone Menggunakan Metode Simple Additive Weighting.Skripsi.Universitas Dian Nuwantoro Semarang.

[4] Fauzan, R. \& Siahaan, Daniel Oranova. 2014. Pos Tagging Bahasa Indonesia Dengan Maximum Entropy Menggunakan Stanford Postagger. POLHASAINS, 26-30.

[5] Fauzan, R. \& Sarifah. 2016. Sistem Prediksi Jumlah Produksi Padi Pada Kabupaten Barito Kuala Dengan Menggunakan Metode KNearestneighbor (Knn). PHASTI, 24-31.

[6] Kurniawan,D. (2010). Evaluasi Sistem temu kembali informas model ruang vector dengan pendekatan user judgement, Jurusan Matematika Program Studi Ilmu Komputer FMIPA Universitas Lampung. Lampung: Universitas Lampung.

[7] Liang, T. A. (2005). Decision Support System and Intelligent System 7th Edition. New Delhi: Prentice'Hall of India.

[8] MacCrimmon, K. R. 1968, Decision Making among Multiple Attribute Alternatives: a Survey and Consolidated Approach.

[9] Rhozi,L.F,2016. Sistem Pendukung Keputusan Pemilihan Smartphone Android Menggunakan Metode Simple Additive Weighting (SAW). Skripsi. Universitas Nusantara PGRI Kediri, Kediri.

[10] Ristekdikti, 2017. Pedoman Bidik Misi 2017. Jakarta : Ristekdikti.

[11] Ramadhana, Rizka, H, "Sistem Pendukung Keputusan Pemilihan Jurusan pada MAN 1 Banjarmasin Menggunakan Metode Weighted Produk”. POLIBAN, Banjarmasin, Indonesia. 2016.

[12] Rinaldhi, Galih Eka, "Penerapan Metode Simple Additive Weighting (SAW) untuk Sistem Pendukung Keputusan Penentuan Penerimaan Beasiswa bantuan Siswa Miskin (BSM) pada SMA Negeri 1 Subah Kab. Batang”, UDN, 2013.

\section{IV.PENUTUP}

